\title{
Corrigendum: Adaptive Resonance Theory Training Parameters: Pretty Good Sets
}

\author{
${ }^{1}$ Taisir Mohammad Eldos and ${ }^{2}$ Abdulaziz Suleiman Almazyad \\ ${ }^{1}$ Department of Computer Engineering, \\ Jordan University of Science and Technology, Al Ramtha, Irbid Jordan \\ ${ }^{2}$ Department of Computer Engineering, College of Computer Engineering and \\ Sciences, King Saud University, Riyadh 11451, Saudi Arabia
}

\begin{abstract}
Correction to: Journal of Computer Science http://doi.org/10.3844/jcssp.2010.1443.1449, published online 01 December 2010; updated 11 April 2018
\end{abstract}

The original version of this Article contained errors in the affiliation for Tasir Eldos.

The correct affiliation for Mr. Tasir Eldos is as follows:

Department of Computer Engineering,

Jordan University of Science and Technology, Al Ramtha, Irbid Jordan

These errors have now been corrected in the HTML and PDF versions of the Article.

http://doi.org/10.3844/jcssp.2018.436 